Chapter 25

\title{
The Controversial Vascular Access for Hemodialysis - Own Experience
}

\author{
M. Dziekiewicz, G. Kade, Z. Wańkowicz and \\ M. Maruszyński
}

Additional information is available at the end of the chapter

http://dx.doi.org/10.5772/53913

\section{Introduction}

Over the last ten years the number of patients requiring dialysis has been growing at a rate of nearly $10 \%$ per year. This trend, noted in both the United States and Europe [1], is likely to continue during the years to follow. Since 1966 the preferred vascular access for hemodialysis (HD) has been the arteriovenous fistula (AVF) [2]. However, despite the experience amassed over the years, vascular access dysfunction still remains the main reason for hospitalization of patients undergoing dialysis [3]. Because of this creation of an access in the lower limb or a complex bypass surgery using artificial material may be necessary in some patients. This chapter describes some of the complex surgical procedures likely to be alternatively implemented in cases of a problematic vascular access [4].

\section{Surgical interventions}

\subsection{The contra lateral internal jugular vein bypass}

In patients with an impatent brachial fistula caused by the ipsilateral central vein occlusion or stenosis the contralateral jugular vein (IJV) bypass can be used [5]. The patient is anesthetized in the decubitus position with the head turned toward the thrombosed fistula. An incision is made in the neck along the anterior side of the sternocleidomastoid muscle. Than the IJV is dissected. Next, an incision is made high in the arm to dissect and declot the fistula by using a Fogarty's catheter. A subcutaneous tunnel running on the anterior aspect of the chest is created and the polytetrafluoroethylene (PTFE) graft is passed through accompanied 
by the intravenous injection of heparin. The distal anastomosis is made with the 5-0 end-toside polypropylene running suture with the declotted part of the fistula by using the incision made for the Fogarty's catheter introduction. The proximal anastomosis to IJV is created using the same suture. Technically, vascular surgeons are familiar with the procedure, but this particular intervention has not been commonly used.

\subsection{The femorofemoral crossover bypass}

The patient is anesthetized in a supine position. The femoral artery and vein are dissected on both sides through small incisions in the groins. A subcutaneous tunnel is created on the anterior aspect of the lower part of the abdominal wall bellow the umbilicus. Heparin is injected intravenously and the graft is passed through the tunnel. The connection of the graft with the arterial part of the fistula is made by the end-to-side anastomosis with the common femoral artery using the 5-0 polypropylene running suture. Next, a connection is made by the end-to-side anastomosis with the common femoral vein using the same suture [6]. This procedure is dedicated to a group of patients in whom several AVFs created in the upper arms have eventually failed [7]. Potential infectious complications should by considered prior to the surgical intervention. One of the underestimated, but very important factors to be taken into account, especially when a patient is a young woman, is the cosmetic result of the operation.

\subsection{The necklace bypass}

A generally anesthetized patient is placed in the decubitus position with the elevated shoulders. Surgical approach to the subclavian vessels is gained by the one-cm incisions below each clavicle. The pectoralis major is dissected, the fascia opened and the pectoralis minor dissected and split. Than the axillary artery and vein are dissected. Next, a subcutaneous tunnel is created running in front of the superior $1 / 3$ of the sternum. The graft is passed through the curved tunnel. Heparin injection is a common procedure. The venous anastomosis is made using the 5-0 polypropylene running suture. The arterial anastomosis is obtained with the same way. Finally, to control the hemostasis the graft is flushed with blood $[7,8]$.

\subsection{The axillary loop}

For creation of the axillary loop the same technique as above is used including the surgical approach, prosthesis, and sutures, but the graft tunnel is longer extending from the axillary artery to the axillary vein. However, elongation of the graft increases the risk of infection, clotting, stenosis, and occlusion $[7,8,9]$.

\subsection{The saphenous vein transposition}

We used this technique as described by Gradman and Pierre-Paul [10,11] in one patient with the bilateral obstruction of the brachiocephalic veins. The patient was neither diabetic nor obese. Mobilization of the saphenous vein (SV) provides an exceptionally long arm of the 
fistula. Creation of the U-shaped tunnel and the anastomosis between SV and the ipsilateral common femoral artery is needed. Unfortunately, as the fistula is placed in a very fragile skin area each punction is painful and the risk of infection is high. Theoretically, however, the SV transposition gives a very good vascular access for HD with all its pros and cons in a selected group of patients.

\subsection{The axillary artery to the popliteal vein bypass}

This bypass, used as the arteriovenous fistula, was first described in 2004 by Calder et al [12]. The authors performed this technique in five patients who were either obese or diabetic and presented symptoms of the superior vena cava obstruction. In addition, these patients could not undergo peritoneal dialysis because of a previous failure of the technique, obesity, or a previous major abdominal surgery. Being aware of the disadvantages such as the risk of infection, occlusion, stenosis etc. associated with a long graft created for other vascular indications as well as the unsatisfactory long-term patency of the graft in e.g. atherosclerotic patients we do not recommend this type of fistula to be performed in such patients.

\subsection{The femoral artery to the right atrium bypass}

In this type of the fistula the cardiopulmonary bypass is not necessary. The patient is anesthetized in a decubitus position and the median sternotomy is performed. Then, the pericardium is incised and the heart and the great trunks are dissected. Next, the right Scarpa is incised and the femoral artery with its branches are dissected. A subcutaneous tunnel is created along the lateral aspect of the abdomen and the chest wall. Just before the second intercostal space an incision is made laterally on the chest. The graft is passed through the incision to the chest and anastomosed to the atrium. The distal anastomosis is created endto-side with the superficial femoral artery. A patient qualified to this procedure should not be eligible for peritoneal dialysis or transplantation [7]. Since this procedure is most challenging for both the patient and the surgeon indications for it should be strictly limited to a carefully selected group of patients. Indeed, we support the opinion expressed by some other authors who call this kind of access "exotic". However, in spite of all the shortcomings there are conditions in which application of this technique can be the only effective renal replacement therapy.

\section{Summary}

In certain clinical situations a surgeon faces the problem of the AVF creation in patients who have undergone several surgical interventions and, in addition, are in their 70's or 80's. Moreover, there are no simple and clear protocols for selecting the type of the vascular access in hemodialysis. There are, however, some practical clues. For example, in patients with no possibility to create AVF in the upper limb a saphenous vein loop to the femoral artery is recommended. Also, transposition to the popliteal artery or a loop graft to the femoral artery can be performed. As indicated above, long saphenous vein fistulas are associated with 
the low patency rate $[7,11]$ requiring several additional interventions [7]. Because of the manipulation in the Scarpa's triangle each femoral graft is associated with the risk of infection and poor and prolonged wound healing. Hence, most surgeons advocate that this procedure be used in patients with the central venous stenosis or occlusion who are not candidates for peritoneal dialysis and are neither obese nor diabetic. For the latter patients most authors recommend the axillopopliteal bypass. The main benefit of this AVF is avoidance of the involvement of the femoral triangle $[7,12]$.

Most vascular surgeons refrain from creating long bypasses, but those who specialize in AVF approve of them since the long fistula arm allows avoiding the sharp angulation of the graft [13]. Moreover, long bypasses offer a larger area for cannulation. In turn, as described by Chemla et al. [7], the left femoral artery to the right atrium bypass functioned successfully for only three months. For the same group of patients Karp et al. [14] preferred to use the renal vein as the outflow because of the ostensibly decreased morbidity associated with this intervention. However, several revisions were needed in the patient treated by these authors. The indications to create this kind of AVF should be regarded as the last-chance measure in a patient who cannot be switched to peritoneal dialysis or undergo transplantation [7].

The axilloaxillary bypass has been described previously, but long term results have not been satisfactory although good results and patent grafts were obtained in individual cases $[7,12]$. This AVF is recommended for patients with the unilateral subclavian artery or vein occlusion. The necklace bypass seems to be a reasonable solution for patients at risk of the steal syndrome [9]. The femorofemoral bypass can be an option for patients who care for cosmetic problems because in this case the cicatrix is minimal and hidden behind the panty line $[7,12]$.

The problems in functioning of AVF after complete thrombosis of the ipsilateral subclavian vein and IJV may be solved by using a jump graft from the fistula to the contralateral IJV $[7,15]$. This way HD can be continued without the need for the temporary catheter insertion and the fistula can be immediately cannulated [7].

Noticeably, each difficult and complex patient with the history of several surgical interventions in all the limbs should be carefully and individually analyzed. Only a vascular surgeon experienced in AVF can perform the most difficult operations aimed at creating rare fistulas. Another important thing is to minimize the operating risk which is aggravated when the central vessels are used for the AVF creation. Some of the proposed AVF are challenging and most of us will never have the opportunity or the need to make them. As shown by the last ten years endovascular procedures proved to be the powerful tools that have significantly changed our vascular access strategy. Currently, most of the vascular departments are equipped with angiographs allowing to perform angioplasty of a stenosis or a local thrombolysis of the clotted fistulas. Percutaneous angioplasty can be supplemented by implantation of a stent [16]. 


\section{Author details}

M. Dziekiewicz ${ }^{1 *}$, G. Kade ${ }^{2}$ Z. Wańkowicz² and M. Maruszyński²

*Address all correspondence to: dziekiewicz@wp.pl

1 Department of Vascular \& Endovascular Surgery, Military institute of Medicine, Warsaw, Poland

2 Department of Nephrology, Military institute of Medicine, Warsaw, Poland

\section{References}

[1] US Renal Data system, USDRS 2002 Annual data report: Atlas of end stage renal disease in the United States. National Institute of Health, National Institute of Diabetes and Digestive and Kidney diseases, Bethesda, MD;2002.

[2] Brescia M, Cimino J, Appel $\mathrm{K}$ et al. Chronic hemodialysis using venipuncture and a surgically created arteriovenous fistula. N Engl J Med 1996;275:1089-92.

[3] Dziekiewicz M., Maruszyński M. Dostęp chirurgiczny do hemodializy i dializy otrzewnowej. Pol Arch Med. Wewn 2003, CX, 4, 10, 1245-1251.

[4] Dziekiewicz M, Obara A, Zagrodzka M et al. „Trudny” dostęp naczyniowy u chorych leczonych nerkozastępczo hemodializami. Valetudinaria - Postępy Medycyny Klinicznej i Wojskowej, 2004, 9, 1, 17;49-54.

[5] Weeks SM. Unconventional venous access. Tech Vasc Interv Radiol 2002;5(2):114-20.

[6] Hazinedaroglu S, Tuzuner A, Ayli D et al. Femoral vein transposition versus femoral loop grafts for hemodialysis: a prospective evaluation. Transplant Proc 2004;36:65-67.

[7] Chemla E, Korrakuti L, Makanjuola D et al. Vascular access in hemodialysis patients with central venous obstruction or stenosis: one center's experience. Ann Vasc Surg 2005;19:692-98.

[8] Morsy MA, Khan A, Chemla ES. Prosthetic axillary-axillary arteriovenous straight access (necklace graft) for difficult hemodialysis patients: a prospective single-center experience. J Vasc Surg 2008;48(5):1251-4.

[9] McCann R. Axillary grafts for difficult hemodialysis access. J Vasc Surg 1996;24:457-62.

[10] Gradman W, Pozrikidis C. Analysis of options for mitigating hemodialysis access-related ischemic steal phenomena. Ann Vasc Surg 2004;18:59-65.

[11] Pierre-Paul D, Williams S, Lee T, et al. Saphenous vein loop to femoral artery arteriovenous fistula: a practical alternative. Ann Vasc Surg 2004;18:223-27. 
[12] Calder F, Chemla E, Anderson L et al. The axillary artery-popliteal vein extendedpolytetrafluoroethylene graft: a new technique for the complicated dialysis access patient. Nephrol Dial Transplant 2004;19:998-1000.

[13] Chateau F, Duisit J, Lengele B and Vanwijck R. Techniques for coverage of infected vascular grafts. Acta Chir Belg 2010;110(4):487-91.

[14] Karp S, Hawxby A, Burdick J. Axillorenal arteriovenous graft: a new approach for dialysis access. J Vasc Surg 2004;40:379-80.

[15] Nortley M, Brett A, Fossati N and Chemla ES. Retroesophageal internal jugular-tointernal jugular vein bypass for venous occlusion in a patient with complex hemodialysis access. J Vasc Surg 2009;50(6):1490-2.

[16] Tourmel-Rodrigues L, Pengloan J, Baudin S et al. Treatment of stenosis and thrombose in hemodialysis fistulas and grafts by interventional radiology. Nephrol Dial Transplant 2000;15:2029-36. 